\title{
Improving subtropical boundary layer cloudiness in the 2011 NCEP GFS
}

\author{
J. K. Fletcher ${ }^{1}$, C. S. Bretherton ${ }^{2}$, H. Xiao ${ }^{3}$, R. Sun ${ }^{4}$, and J. Han ${ }^{5}$ \\ ${ }^{1}$ Monash University, Clayton, Victoria, Australia \\ ${ }^{2}$ University of Washington, Seattle, Washington, USA \\ ${ }^{3}$ Pacific Northwest National Laboratory, Richland, Washington, USA \\ ${ }^{4}$ IMSG at NOAA/NWS/NCEP/EMC, Camp Springs, Maryland, USA \\ ${ }^{5}$ SRG at NOAA/NWS/NCEP/EMC, Camp Springs, Maryland, USA
}

Correspondence to: J. K. Fletcher (jennifer.fletcher@monash.edu)

Received: 21 February 2014 - Published in Geosci. Model Dev. Discuss.: 9 April 2014

Revised: 6 August 2014 - Accepted: 6 August 2014 - Published: 23 September 2014

\begin{abstract}
The current operational version of National Centers for Environmental Prediction (NCEP) Global Forecasting System (GFS) shows significant low cloud bias. These biases also appear in the Coupled Forecast System (CFS), which is developed from the GFS. These low cloud biases degrade seasonal and longer climate forecasts, particularly of short-wave cloud radiative forcing, and affect predicted sea surface temperature. Reducing this bias in the GFS will aid the development of future CFS versions and contributes to NCEP's goal of unified weather and climate modelling.

Changes are made to the shallow convection and planetary boundary layer parameterisations to make them more consistent with current knowledge of these processes and to reduce the low cloud bias. These changes are tested in a singlecolumn version of GFS and in global simulations with GFS coupled to a dynamical ocean model. In the single-column model, we focus on changing parameters that set the following: the strength of shallow cumulus lateral entrainment, the conversion of updraught liquid water to precipitation and grid-scale condensate, shallow cumulus cloud top, and the effect of shallow convection in stratocumulus environments. Results show that these changes improve the single-column simulations when compared to large eddy simulations, in particular through decreasing the precipitation efficiency of boundary layer clouds. These changes, combined with a few other model improvements, also reduce boundary layer cloud and albedo biases in global coupled simulations.
\end{abstract}

\section{Introduction}

The National Centers for Environmental Prediction (NCEP) Global Forecast System (GFS, http://www.emc.ncep.noaa. gov/GFS/doc.php) is an important model for operational weather forecasting. A frozen version of the GFS is coupled to the Modular Ocean Model v4 (http://www.gfdl.noaa.gov/ mom-ocean-model) and called the Coupled Forecast System (CFS); this is used for seasonal to inter-decadal climate predictions and reanalyses (Saha et al., 2006, 2010). An outstanding problem for both the GFS and CFS, described in more detail below, is the representation of boundary layer clouds. We focus on improving parameterisation of these clouds and their associated processes in the GFS, using insights gained from parameterisation development work in climate models and studies using large eddy simulation.

This research was conducted collaboratively by researchers at the University of Washington and NCEP, funded as part of a NOAA-funded Climate Process Team (CPT) on the stratocumulus-cumulus transition. The purpose of the CPT was to improve the representation of subtropical boundary layer cloud processes in the GFS and CFS, as well as in the Community Earth System Model (CESM, http://www.cesm.ucar.edu/), using the relative strengths and weaknesses of these two rather different modelling systems to help inform further parameterisation advances in both models. The CPT has also involved researchers from the Jet Propulsion Laboratory, University of California Los Angeles, the National Center for Atmospheric Research (NCAR), and Lawrence Livermore National Laboratories. 
It is anticipated that Version 3 of the CFS will be developed from an upcoming operational version of the GFS, making current biases in the GFS relevant to forecasts of seasonal and longer timescales. Xiao et al. (2014) presented our CPT's comparisons of the simulated climate from multidecadal free-running simulations using an ocean-coupled version of the GFS operational in late 2011 with comparable simulations using Version 1 of the CESM (which uses the Community Atmosphere Model Version 5, or CAM5, as its atmospheric component). They found that the simulated GFS climatology was of comparable or higher quality to those with CESM1, except for cloud cover and radiative properties. The GFS-simulated global short-wave and longwave cloud radiative effects were only about half as large as observed, with profound effects on the simulated planetary energy budget. Xiao et al. (2014) found that much of this response was attributable to inadequate cloud cover over most parts of the oceans, including the near-coastal part of the subtropical stratocumulus regions and tropical-subtropical shallow cumulus regions. On the other hand, one of the few regions in which cloud cover and radiative effects were overestimated in GFS is in the stratocumulus to cumulus transition regions, especially the East Pacific between the equator and $30^{\circ} \mathrm{S}$; the model fails to accurately represent the coastal/open ocean contrast in cloud cover in addition to an global mean low bias. Thus, by focusing on the simulation of boundary layer clouds in the eastern subtropical oceans, we also hope to improve GFS-simulated cloud climatology in many other regions and globally averaged cloud radiative properties.

One focal strategy of the CPT is to use benchmark singlecolumn model tests to identify possible model improvements, which are then tested in short global integrations. This paper describes some initial efforts to implement this strategy for improving GFS cloud simulations.

\section{Method}

\subsection{Model availability}

We use GFS version 11.0.6 for both single-column and global model experiments. The GFS single-column model (SCM) used in this study, as well as the forcing files, can be downloaded at http://www.atmos.washington.edu/ jkf/ GFS_SCM.html, which also includes instructions for running the SCM as well as routines modified for the experiments described in this paper. The global model may be downloaded at http://www.nco.ncep.noaa.gov/pmb/codes/ nwprod/sorc/global_fcst.fd/. The shallow convection and boundary layer scheme subroutines used in the single column model experiments are also available in the Supplement.

\subsection{Single-column modelling}

The SCM has proven a useful tool in testing general circulation model (GCM) physics on properties like clouds and precipitation in isolation from the effects of large-scale circulations (Randall et al., 2003). GCM developers can use SCMs to compare model performance to that of high resolution models such as large eddy simulation (LES) by running both with the same set of observationally derived forcings. These forcings specify the initial thermodynamic and wind profiles, the tendencies of these profiles over the course of the simulation, and either the sea surface temperature or the surface latent and sensible heat fluxes. As part of the GEWEX Cloud System Study (GCSS, now subsumed into the Global Atmospheric System Study or GASS), a rich set of forcing cases exists for this purpose, drawn from observational field campaigns encompassing different environments ranging from nocturnal marine stratocumulus to continental deep convection (e.g. Siebesma et al., 2003; Stevens et al., 2005; Grabowski et al., 2006).

The GFS has seldom been subject to this type of testing in the past, with developers generally focusing on global model skill scores based on errors of meteorological variables such as $500 \mathrm{hPa}$ heights. Investigations of GFS physics that have used the single-column modelling approach have been oriented toward cirrus clouds and ice phase microphysics (e.g. Luo et al., 2005). In single-column mode, we compare quantities relevant to the physics of warm boundary layer clouds, such as cumulus updraught mass flux and thermodynamic properties, to those of identically forced LES, using observationally anchored cases. While single-column modelling cannot substitute for sensitivity tests using 3-D simulations, this method's relative simplicity and comparability with LES makes it a useful tool for falsifying model physics and as a reference to guide interpretation of global model results.

Our approach thus far in using SCM to improve model physics has been to identify components of the parameterisations most relevant to boundary layer clouds that are (a) formulated in ways that are inconsistent with current knowledge of the process in question and (b) possible sources of model bias. We then aim to improve the component of the scheme while maintaining the general framework of the parameterisation. In other words, while, for example, the "dual mass flux" scheme of Neggers et al. (2009) is an attractive framework for unified parameterisation of large boundary layer eddies and shallow convection, to implement this in the GFS would require a complete overhaul of both the boundary layer and shallow convective schemes. Maintaining and improving the current framework is a more pragmatic approach to improving GFS physics in the short term. In some cases, sensitivity experiments comparing SCM to LES can identify sources of compensating errors, in which case simultaneous improvements must be made to several aspects of the physical parameterisations to reduce simulation biases.

The LES runs we compare to the SCM in this study use version 6 of the System for Atmospheric Modeling (SAM, Khairoutdinov and Randall, 2003). In all runs, SAM resolves the largest boundary layer eddies and all clouds, while smaller-scale turbulence and microphysics are 
parameterised. SAM has been included in LES intercomparison studies for the GCSS cases used here (Siebesma et al., 2003; Stevens et al., 2005) and has been shown to reproduce observed precipitation, liquid water path, surface fluxes and cloud fraction (where such observations are available) in those cases, except where we note otherwise.

\subsection{Global model experiments}

We also ran global model tests that complement our SCM experiments. Because global coupled-model experiments are far more computationally expensive than single-column experiments, we performed only three global experiments, with parameter changes chosen based partially on SCM results and partially on simultaneous development strategies at NCEP.

As in Xiao et al. (2014), we use the NCAR Atmospheric Modeling Work Group/Working Group on Numerical Experimentation diagnostic package (http://www.cgd. ucar.edu/amp/amwg/diagnostics) to facilitate comparison of our global model experiments with observations.

\section{Model overview}

This study is based on the 2011 version of GFS, the same as that used in the single-column model. It has a spectral triangular truncation of 126 waves (T126), equivalent to roughly one degree horizontal grid spacing, and 64 hybrid sigma pressure levels (Sela, 2009). Compared with the previous version of the GFS, the main changes are in the parameterisations of the shallow convection, the planetary boundary layer (PBL) and deep convection (Han and Pan, 2011). Features of these schemes are described in more detail in the next section.

This version of GFS uses the Atmospheric and Environmental Research Inc. Rapid Radiative Transfer Model (RRTM) long-wave parameterisation (Mlawer et al., 1997). The short-wave parameterisation is modified from the National Aeronautics and Space Administration (NASA) Goddard Space Flight Center solar radiation scheme (Hou et al., 2002; Chou et al., 1998). Both radiation schemes assume maximum random cloud overlap.

The microphysics scheme (Zhao and Carr, 1997; Moorthi et al., 2001) prognoses cloud water specific humidity and cloud fraction following Sundqvist (1978). Both stratiform cloud processes and detrained cumulus cloud ice and condensate are sources of total cloud water.

For the global simulations presented below, the GFS is coupled to the Modular Ocean Model 4 (MOM4), a finite difference version of the ocean primitive equations (Griffies et al., 2005). The zonal resolution is $1 / 2$ degree. The meridional resolution gradually decreases from $1 / 4$ degree near the equator to $1 / 2$ degree at high latitudes. There are 40 height layers, whose vertical spacing increases from $10 \mathrm{~m}$ near the surface to about $500 \mathrm{~m}$ in the bottom.

\section{Physics parameterisations}

This section summarises the GFS shallow convection, planetary boundary layer (PBL), and cloud fraction parameterisations, focusing on aspects relevant to our sensitivity tests. More detailed descriptions of these schemes are given by Troen and Mahrt (1986), Hong and Pan (1996) and Han and Pan (2011).

\subsection{Shallow convection}

The GFS shallow cumulus scheme (Han and Pan, 2011) is a bulk entraining plume mass flux parameterisation based on the GFS deep convection scheme (Pan and Wu, 1995; Han and Pan, 2011), but with new formulations of lateral entrainment and detrainment rate, a different mass flux closure, and different plume microphysics.

The bulk plume originates from and shares the properties of the level of highest moist static energy (MSE) in the boundary layer, usually the lowest model level. It rises to its lifted condensation level, where its mass flux is determined using the Grant (Grant and Brown, 1999) closure. The plume mass flux $m$ is given by the equation

$\frac{1}{m} \frac{\mathrm{d} m}{\mathrm{~d} z}=\epsilon-\delta$,

where $\epsilon$ is the fractional lateral entrainment rate and $\delta$ the fractional detrainment rate. The former is assumed to have the form $\epsilon=c / z$, where $c$ is an adjustable nondimensional constant. The fractional detrainment rate $\delta$ is constant with height and equal to the fractional entrainment rate at the height of cloud base. This ensures a mass flux profile that decreases with height within the cumulus updraft, consistent with the LES study of Siebesma and Cuijpers (1995). It also means that changes to $c$ affect the detrainment rate as well as the entrainment rate. The same entrainment rate is used in determining the moist static energy and total water specific humidity (and hence the buoyancy) of the cumulus updraught, as well as its horizontal velocity, relevant for cumulus momentum transport.

The bulk plume microphysics are simple: updraught liquid water is converted to precipitation (which falls down through the plume and can evaporate in the subcloud layer), and it is detrained to grid-scale cloud condensate, both at rates proportional to the updraught liquid water content, following Lord (1978):

$q_{c}^{\mathrm{prec}} \propto c_{0} q_{c}^{\mathrm{cu}}$

and

$q_{c}^{\mathrm{detr}} \propto c_{1} q_{c}^{\mathrm{cu}}$. 
The scheme contains a flag that turns off shallow convection if the cloud top (constrained to a model level) is below the model-diagnosed PBL top, diagnosed with a bulk Richardson number. This ensures that clouds that lack the buoyancy to penetrate the inversion are handled entirely by the PBL scheme rather than the shallow convection scheme. In the operational GFS, this flag is commented out because it has little impact on NCEP's traditional forecast skill metrics. Our tests, discussed below, showed that this may nevertheless often be important to the parameterised boundary-layer cloud cover and precipitation.

Shallow cumulus cloud top is determined by cloud work function (Arakawa and Schubert, 1974), i.e. the vertically integrated buoyancy of the entraining updraught. Updraughts are given energy equal to $10 \%$ of cloud work function to overshoot their level of neutral buoyancy. We test an alternative formulation of cloud top that instead uses an equation for the square of the cumulus updraught vertical velocity $w$ :

$\frac{1}{2} \frac{\mathrm{d}\left(w^{2}\right)}{\mathrm{d} z}=a B-b \epsilon w^{2}$,

where $a$ and $b$ are tunable parameters and $B$ is the cumulus updraught buoyancy. Choosing the parameters such that $b / a>1$ roughly parameterises the effect of perturbation pressure gradients on vertical velocity (Bretherton et al., 2004).

Key parameters in the shallow convection scheme that affect its performance include the fractional entrainment/detrainment parameter $c$ used in Eq. (1) and the rates $c_{0}$ and $c_{1}$ in Eqs. (2) and (3), respectively. If Eq. (4) is used to determine cloud top, then $a$ and $b$ may also be important parameters.

\subsection{PBL turbulence and stratiform clouds}

The GFS boundary layer turbulence parameterisation (Hong and Pan, 1996) is an eddy diffusivity scheme modified from Troen and Mahrt (1986) with an added "countergradient" term (for temperature only) representing the nonlocal mixing done by the largest PBL eddies. Han and Pan (2011) modified the turbulence scheme by adding a simple parameterisation of cloud-top-driven mixing after Lock et al. (2000). This entrainment rate is proportional to the radiative flux jump across cloud top and represents cloud top cooling enhancement of boundary layer entrainment. The original Lock scheme also parameterised mixing-induced buoyancy reversal; this process is not included in the GFS scheme.

The operational GFS uses two different cloud fraction schemes: one for radiative flux calculations, the other for stratiform microphysics calculations. The radiation scheme uses the Xu and Randall (1996) fit of observed cloud fraction to relative humidity $\mathrm{RH}$, condensate specific humidity $q_{1}$, and saturation specific humidity $q_{\mathrm{s}}$ :

$\sigma_{\mathrm{XR}}=\mathrm{RH}^{k_{1}}\left(1-\exp \left\{-\frac{k_{2} q_{1}}{\left[(1-\mathrm{RH}) q_{\mathrm{s}}\right]^{k_{3}}}\right\}\right)$.
The model uses the original Xu and Randall (1996) empirical values for the fit parameters: $k_{1}=0.25, k_{2}=100, k_{3}=0.49$. However, the condensate specific humidity used is only that of the stratiform microphysics scheme. Thus, cumulus convection only interacts with radiation indirectly through its effect on large-scale temperature and moisture fields. The stratiform microphysics scheme is derived from Sundqvist (1978) and parameterises cloud fraction based on relative humidity in excess of a prescribed, latitudinally varying critical RH. The cloud fraction used in the Sundqvist scheme affects the model indirectly through the autoconversion and largescale condensation rates. To maintain consistency with the rest of the scheme the Sundqvist formulation must be used. However, the $\mathrm{Xu}$ and Randall scheme matches observations better in general and is preferable for the radiation scheme. CPT members at NCEP are developing a single cloud fraction scheme to be used throughout the model in future GFS versions.

\section{Single-column results}

\subsection{Model setup}

The SCM is based on the operational version of the GFS, including the same 64 vertical levels, with vertical spacing in the PBL of 50-100 m. We run the SCM with a 5 min time step (half that used in the global simulations we present later in this paper), but the radiation scheme is called once per hour as in the GFS. In single-column mode, horizontal tendencies in wind, temperature, and moisture fields are prescribed by the forcing file in place of large-scale dynamics. The winds at each level are also forced by Coriolis and pressure gradient forces, taking the initial wind profile as the geostrophic wind. The SCM's physical parameterisations are identical to those of the operational GFS except for options to include a few minor modifications planned for future GFS versions. These are discussed below and evaluated in our sensitivity experiments. Our single-column sensitivity tests use two GCSS cases, described below.

\subsection{BOMEX}

For sensitivity tests to changing parameters in the shallow convection scheme, we utilise a nonprecipitating quasisteady oceanic shallow cumulus case presented by Siebesma et al. (2003), derived from the Barbados Oceanographic and Meteorological Experiment (BOMEX, Holland and Rasmusson, 1973). The specified forcings already include the effects of radiative cooling, and cloud-radiation interaction is not considered in this case, so the radiation schemes are turned off in the SCM and the LES. 


\subsubsection{Experiment description}

We use the BOMEX case to study model sensitivity to changing aspects of the shallow convection scheme. In accordance with the discussion in Sect. 2.2, we test model sensitivity to changing several parameters. These parameter changes are summarised on Table 1. First, in the ShCuCldCover experiment, we include cumulus updraught condensate in the cloud fraction parameterisation (Eq. 5). This change is included in subsequent experiments as well.

Second, we test sensitivity to the updraught lateral entrainment rate, parameterised as $\epsilon=c / z$. We run experiments with LES-compatible choices of $c$ in the range of 1.0-2.0 (Siebesma et al., 2003) instead of the operational value $c=$ 0.3 . Because the GFS parameterises updraught detrainment rate as constant with height and equal to the entrainment rate at cloud base (where it is maximum within the cloud), changing $c$ also changes the detrainment rate. For this reason, we will henceforth refer to $c$ as the entrainment/detrainment parameter.

At the same time, we test sensitivity to the efficiency of conversion of updraught condensate into precipitation or detrained condensate. The operational GFS converts updraught condensate in a grid layer to precipitation and detrains it to grid-scale condensate at rates given in Eqs. (2) and (3); both rates are proportional to the condensate mixing ratio. This means that any updraught condensate is precipitated out over an e-folding depth of $400 \mathrm{~m}$, causing extremely efficient precipitation even from the shallowest cumulus clouds. In practice, this compensates for the inadequate dilution of updraught condensate by lateral mixing, as we describe further below. In configuration NewEntr, we decreased these rates - in combination with increases to entrainment - to $c_{0}=0.001 \mathrm{~m}^{-1}, c_{1}=2.5 \times 10^{-4} \mathrm{~m}^{-1}$. This can be regarded as an intermediate step toward the LES results: in NewEntr the lateral entrainment rate is still underestimated, compensated by overestimation of conversion of updraught condensation to precipitation, but both compensating errors are much smaller than with the operational parameter choices.

Lastly, we also show the effect of using the vertical velocity Eq. (4) to determine cloud top. We show the effect of this change both without the NewEntr change (VvelOrig) and with it (VvelNewEntr).

\subsubsection{Results}

Our initial sensitivity tests only involved single parameter changes. This quickly uncovered compensating errors - multiple parameters incorrectly tuned such that their effects cancel each other - in the shallow cumulus scheme. For example, only increasing the updraught lateral entrainment rate resulted in a simulation with an improved mass flux profile but far too small updraught condensate amount, while only decreasing the precipitation and detrainment conversion rates reduced excess precipitation but produced too much condensate. Furthermore, only reducing one of $c_{0}$ or $c_{1}$ simply shifts precipitation between the shallow convection and stratiform microphysics schemes, with little reduction in overall precipitation. It is necessary to change all of these parameters together in order to address these compensating errors, so we only show results from simulations in which multiple parameters were changed.

Figure 1 shows profiles of liquid water potential temperature and total water specific humidity averaged over hours 3-6 of the BOMEX experiments. We show these primarily to give the reader a sense of the environment being simulated: a fairly well-mixed subcloud layer up to about $500 \mathrm{~m}$, a conditionally unstable cloud layer, and a capping inversion starting slightly above $1400 \mathrm{~m}$. SCM results differ from LES primarily in a less well-mixed subcloud layer, a more stably stratified cloud layer, and excess moisture at the inversion. This last feature is explored more in the forthcoming discussion. Biases are most extreme in the VvelOrig configuration, with profiles that imply far too much mixing with the free troposphere.

A major problem with the control GFS simulation of the BOMEX case is that it over-precipitates. The BOMEX case is idealised, but it is designed to mimic a several-day period during which observers and photographs suggest precipitation was negligible (Siebesma and Cuijpers, 1995), consistent with our LES results. Figure 2a shows time series of surface precipitation for the experiments. The control configuration maintains a convective precipitation rate of $\sim 1.5 \mathrm{~mm} \mathrm{day}^{-1}$, large enough to be a sizable moisture sink to the trade cumulus boundary layer, compensating roughly $30 \%$ of the surface evaporation. NewEntr reduces the convective precipitation by $60 \%$, but does not eliminate the problem because the precipitation flux is still proportional to the updraught condensate specific humidity, ensuring that all shallow convection will precipitate at least a little.

The VvelOrig configuration actually worsens the bias. Later we show that this is due to an overdeepening of cumulus convection. However, in combination with NewEntr, the spurious precipitation is reduced and the shallow convection scheme is prevented from switching off and on as it does in the non-Vvel experiments.

Figure 2 shows that all configurations maintain very small liquid water path (LWP) for the first few hours of simulation. This is because nearly all the cloud water is associated with the shallow convection scheme. At varying times in the simulation, however, the LWP rapidly increases in the Control, ShCuCldCover and NewEntr experiments. This indicates rapid development of stratiform cloud, which only the Vvel change is able to prevent.

Figure 3 shows profiles of stratiform cloud water and cloud fraction from both the stratiform microphysics scheme and the radiation scheme. In the left panel, we see that most of the stratiform condensation responsible for the rise in LWP in Fig. 2b occurs at one model level near cloud top. The reasons for this will be explored below. The right panel shows 
Table 1. Parameter settings for SCM experiments with the BOMEX shallow convection cases. Parameters $a$ and $b$ refer to coefficients in Eq. (4).

\begin{tabular}{llllll}
\hline & Control & ShCuCldCover & NewEntr & VvelOrig & VvelNewEntr \\
\hline ShCu cloud & No & Yes & Yes & Yes & Yes \\
$c$ & 0.3 & 0.3 & 1.0 & 0.3 & 1.0 \\
$c_{0}\left[\mathrm{~m}^{-1}\right]$ & $2.0 \times 10^{-3}$ & $2.0 \times 10^{-3}$ & $1.0 \times 10^{-3}$ & $2.0 \times 10^{-3}$ & $1.0 \times 10^{-3}$ \\
$c_{1}\left[\mathrm{~m}^{-1}\right]$ & $5.0 \times 10^{-4}$ & $5.0 \times 10^{-4}$ & $2.5 \times 10^{-4}$ & $5.0 \times 10^{-4}$ & $2.5 \times 10^{-4}$ \\
$a$ & NA & NA & NA & $\approx \frac{1}{3}$ & $\approx \frac{1}{3}$ \\
$b$ & NA & NA & NA & $\approx 6$ & $\approx 6$ \\
\hline
\end{tabular}
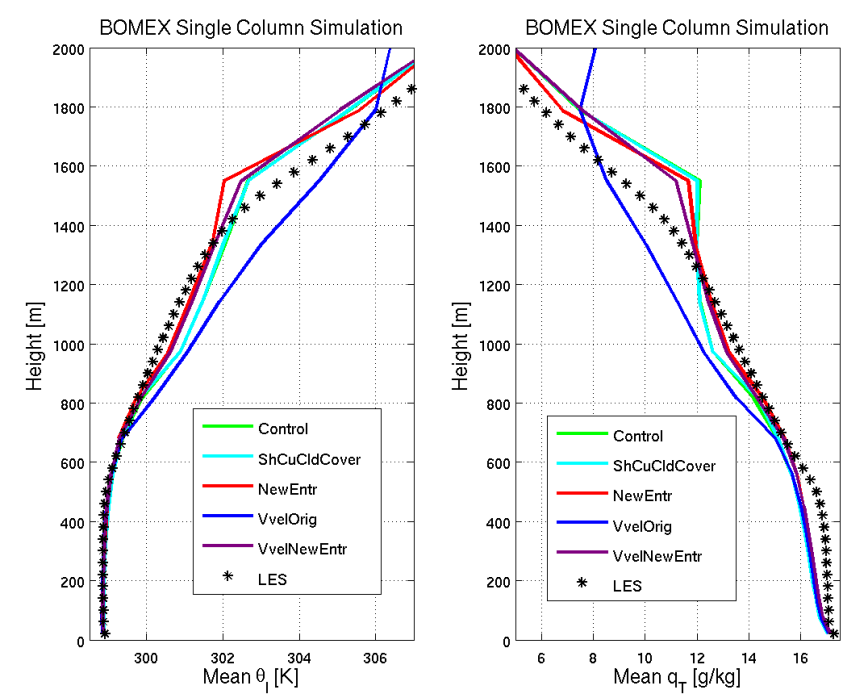

Figure 1. BOMEX liquid water potential temperature (left) and total water (right) profiles averaged over hours 3-6. Coloured lines are different SCM experiments; black stars are LES.

that simply adding cumulus condensate to the radiation cloud fraction - the ShCuCldCover change - is a major improvement, though the bias is now too much cloud cover rather than too little. This bias is reduced by subsequent parameter changes, and the spike in upper PBL cloud cover (and condensate) is removed by the Vvel change. Finally, comparing the middle and right panels shows the large difference that can exist between cloud fraction in the microphysics scheme and that of the radiation scheme.

Figure 4 shows time-averaged cumulus updraught properties: mass flux and condensate specific humidity. For the LES comparison, we define cumulus updraught properties as the average across all LES grid points that are both saturated and have positive vertical velocity.

The mass flux profiles of the Control and ShCuCldCover configurations show the effect of those experiments' high precipitation. Evaporation of rainfall below cloud base overstabilises the subcloud layer, reducing cumulus updraught buoyancy such that convection often extends only one or two grid levels above cloud base - if it is not shut off completely.
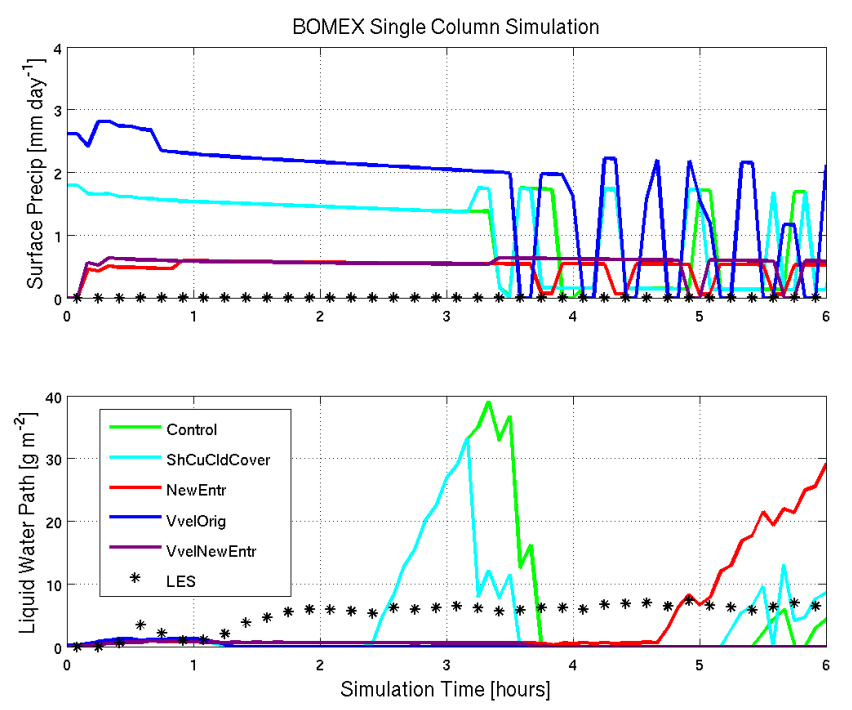

Figure 2. BOMEX time series of surface precipitation rate (top) and liquid water path (bottom) in the first $6 \mathrm{~h}$ of simulation. Coloured lines are different SCM experiments; black stars are LES.

This leads to a time-averaged mass flux profile that is too bottom-heavy and biased low, particularly between 800 and $1200 \mathrm{~m}$. However, the cloud top is in good agreement with LES.

The NewEntr parameter change improves on this by reducing precipitation directly (via the precipitation efficiency $c_{0}$ ) and indirectly (via increased entrainment dilution and reduced mass flux in the upper cloud layer). However, the cloud top is lower than the Control configuration and LES - this is also due to increased entrainment dilution. The tendency of the GFS to produce too-low shallow cumulus cloud top when the entrainment rate is set to a value suggested by current knowledge is in fact why the operational value of $c$ is so small.

The Vvel parameter change increases cloud depth and enhances penetrative entrainment of warm dry inversion air. This is what prevents stratiform condensation in the Vvel runs. With the operational settings for $c, c_{0}$ and $c_{1}$, the bias is overcorrected, with cloud top that is far too high. However, in combination with the NewEntr change, substantial 

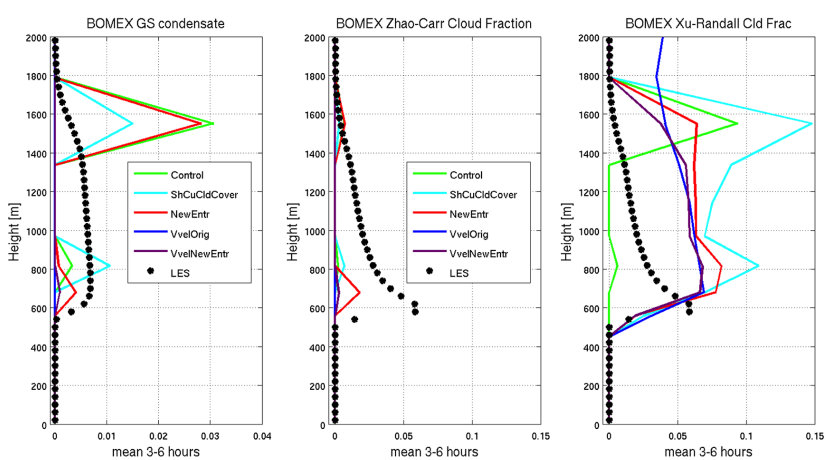

Figure 3. BOMEX grid-scale condensate (left, $\mathrm{g} \mathrm{kg}^{-1}$ ) and cloud fraction as calculated in the stratiform microphysics (centre) and radiation (right) parameterisations, averaged over hours 3-6. Coloured lines are different SCM experiments; black stars are LES.

improvement in the mass flux profile - as well as those shown in previous figures - is seen.

Finally, the right panel of Fig. 4 demonstrates the compensating errors at work in the shallow convection scheme. All configurations produce similar values for cumulus updraught condensate specific humidity, values that are close to that of LES. They do so via different tradeoffs between precipitation and entrainment. A major aspect of our parameter changes has aimed to shift the removal of updraught liquid water content away from precipitation and toward increased mixing with the free troposphere.

\subsection{DYCOMS}

To study model behaviour in a stratocumulus environment, we use a case distilled from the Dynamics and Chemistry of Marine Stratocumulus (DYCOMS-II, referred to hereafter as DYCOMS) Research Flight 1, which sampled a nocturnal, nonprecipitating, well-mixed marine stratocumulus boundary layer under a strong capping inversion in the Northeast Pacific (Stevens et al., 2003). We use the GCSS DYCOMS case forcings as presented by Stevens et al. (2005) and Zhu et al. (2005). However, those studies used an idealised longwave radiation code in their simulations; we use the full model (long-wave only) radiation code in both SCM and LES.

\subsubsection{Experiment description}

We found in our Control DYCOMS simulation that the shallow cumulus scheme was transporting much of the heat and moisture through the PBL despite this being a stratocumulus case (not shown). Recall from Sect. 4.1 that there is a logical flag within the shallow convection scheme code that turns shallow convection off if the cumulus cloud top is at or below PBL top. Thus, in boundary layers where moist updraughts have insufficient energy to penetrate the capping inversion, PBL cloudiness and entrainment will be handled by the PBL

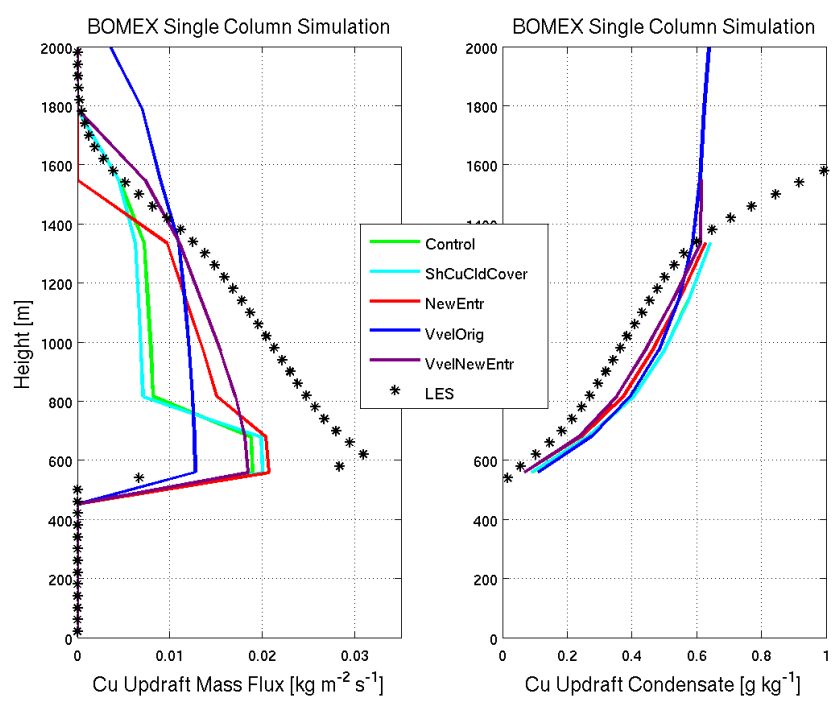

Figure 4. BOMEX shallow cumulus updraught (left) mass flux and (right) condensate profiles averaged over hours 3-6. Coloured lines are different SCM experiments; black stars are LES.

scheme rather than the cumulus convection scheme. This flag is not used by default, even though it is physically reasonable, but we experimented with using it, effectively turning convection off for the duration of the run. This "ShCuFlag" experiment is shown along with the configurations already shown for the BOMEX case. The exception to this is the $\mathrm{ShCuCldCover}$ configuration, which has no effect on the DYCOMS case and is not shown here.

The operational GFS also includes a minimum background diffusion applied both in and above the PBL. The background diffusivity for heat and moisture in the operational GFS decreases exponentially with height from $1.0 \mathrm{~m}^{2} \mathrm{~s}^{-1}$, giving rise to about $0.9 \mathrm{~m}^{2} \mathrm{~s}^{-1}$ at the $900 \mathrm{hPa}$ level, a typical PBL top in marine stratocumulus. To reduce erosion of coastal stratocumulus, NCEP developers have further reduced the lower inversion layers' background diffusivity; it is now $30 \%$ of that at the surface (i.e. $0.3 \mathrm{~m}^{2} \mathrm{~s}^{-1}$; Han and Pan, 2011). Hence, we use this reduced background diffusivity in our DYCOMS simulations.

\subsubsection{Results}

All DYCOMS experiments with the GFS maintain a reasonably strong capping inversion, given the model resolution, and produce cloud fraction of about 1.0 after initial spinup (not shown). In this respect, the DYCOMS SCM simulations do not have the same biases that the global coupled model shows in the Northeast Pacific, where the model generates too shallow boundary layer and too low cloud fraction. This limits the interpretation of SCM results.

Figure 5 shows the evolution of precipitation and LWP. As noted by Stevens et al. (2005), LES models tend to underestimate LWP in the DYCOMS case, which was observed 


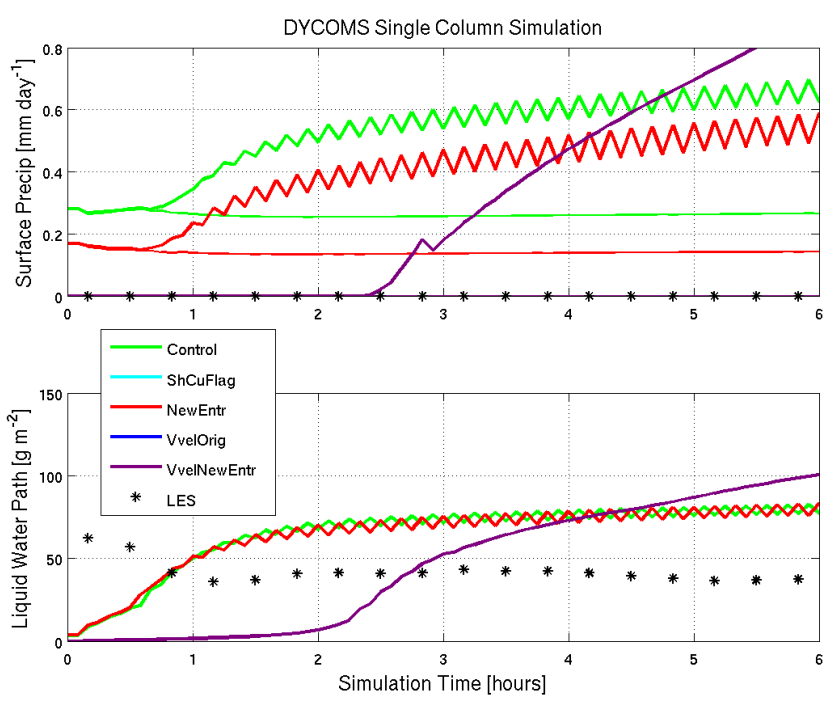

Figure 5. DYCOMS time series of surface precipitation rate (top) and liquid water path (bottom) in the first $6 \mathrm{~h}$ of simulation. Coloured lines are different SCM experiments; black stars are LES. Results are identical for all experiments without shallow convection, thus ShCuFlag and VvelOrig are hidden by VvelNewEntr.

to be about $60 \mathrm{~g} \mathrm{~m}^{-2}$. The SCM LWP is actually closer to observations. However, this is achieved with a drizzle rate of roughly $0.5 \mathrm{~mm} \mathrm{~d}^{-1}$. Both observations (Stevens et al., 2003) and LES indicated no drizzle at the surface or even at cloud base. Thus it appears that, as with the convection scheme, the physics parameterisations controlling stratocumulus are too tuned toward precipitation as a mechanism for PBL drying. The simplest explanation is that the modified Lock et al. (2000) parameterisation in the SCM is not producing enough cloud top entrainment of warm, dry air. Initial results, to be reported in a future study, indicate that increasing the entrainment rate in the Lock scheme while simultaneously decreasing the autoconversion rate in the stratiform microphysics scheme can maintain observed LWP while reducing excess precipitation in the DYCOMS simulation.

The most obvious differences are between (1) the Control and NewEntr experiments, and (2) the ShCuFlag and Vvel experiments. As part of the implementation of using vertical velocity for cloud top prediction, a logical flag turning off shallow convection if it is less than $70 \mathrm{hPa}$ deep is included. Thus, the Vvel configurations look just like the $\mathrm{ShCu}-$ Flag configuration because all of them result in the model turning off shallow convection. Figure 5 shows that, without shallow convection, the model takes $\sim 2.5 \mathrm{~h}$ to spin up cloud LWP despite having a 5 min time step and having been initialised with a supersaturated moisture profile. However, experiments with a different stratocumulus case (not shown) show that this is not the case if the model is initialised with liquid water, and furthermore initialising with liquid water eliminates the oscillations that are seen when the shallow convection scheme is active. These oscillations result from convective precipitation stabilising the subcloud layer and reducing convective mass flux, and hence detrained convective condensate, in the subsequent time step.

\section{Global model results}

\subsection{Configuration and experiment description}

We perform four simulations with the global version of GFS coupled to MOM4: a 50-year run with GFS operational settings; a 1-year control run that, apart from length, is identical to the 50 year run; and two 1-year sensitivity experiments: shortrun1 and shortrun2. Shortrun1 includes most of the parameter changes to the shallow convection scheme suggested by our BOMEX SCM study. Shortrun2 also includes changes suggested by the DYCOMS study and by basic physical considerations not exposed by either SCM case. All experiments are identically initialised on 1 January 1948 . The atmosphere is initialised by NCEP-NCAR reanalysis (Kalnay et al., 1996); the ocean is initialised with the Climate Forecast System Reanalysis (Saha et al., 2010), and the initial state is neutral with respect to the NINO3.4 (El Niño/Southern Oscillation) index. We included ocean coupling for two reasons. First, it corresponds to the setup for seasonal climate prediction, an important application of GFS. Second, it was easier for us to set up a coupled simulation than an uncoupled simulation with seasonally varying sea surface temperatures (SSTs).

The parameter changes in Shortrun1 and Shortrun2 are summarised in Table 2. Shortrunl increases the lateral entrainment rate and reduces the rain conversion rate in the shallow convection parameterisation, following two of the three prescriptions in the BOMEX NewEntr case. Shortrun2 also reduces the condensate detrainment rate (the other parameter change made in NewEntr), uses cumulus condensate for cloud fraction, and uses the vertical velocity Eq. (4) for cloud top. Shortrun 2 also incorporates the additional changes discussed in the DYCOMS ShCuFlag case - to prevent shallow convection with a cloud top that does not extend above the PBL top and to decrease background diffusion in inversion layers. However, the former might have little impact in combination with the vertical velocity cloud top change, as was seen in the DYCOMS simulations.

For physical correctness, a parameterisation of heating due to turbulent kinetic energy (TKE) dissipation is included. We expect this to have negligible impact on any SCM simulation of existing subtropical boundary layer cloud cases. Viscous dissipation of TKE can be a significant source of heat, especially in strong wind conditions such as in hurricanes (Bister and Emanuel, 1998). Although not shown in this paper, inclusion of TKE dissipative heating not only increased the $10 \mathrm{~m}$ maximum wind about $10-30 \%$ in hurricane forecasts, but also largely reduced the unexplained GFS atmospheric energy loss of about $4-5 \mathrm{~W} \mathrm{~m}^{-2}$. These results will 
Table 2. Parameter settings for free-running coupled global model experiments.

\begin{tabular}{llll}
\hline & Control & Shortrunl & Shortrun2 \\
\hline ShCu Cloud & No & No & Yes \\
$c$ & 0.3 & 1.0 & 1.0 \\
$c_{0}\left[\mathrm{~m}^{-1}\right]$ & $2.0 \times 10^{-3}$ & $1.0 \times 10^{-3}$ & $1.0 \times 10^{-3}$ \\
$c_{1}\left[\mathrm{~m}^{-1}\right]$ & $5.0 \times 10^{-4}$ & $5.0 \times 10^{-4}$ & $2.5 \times 10^{-4}$ \\
$a$ & NA & NA & $\approx \frac{1}{3}$ \\
$b$ & NA & NA & $\approx 6$ \\
ShCu Depth Flag & No & No & Yes \\
PBL Bckgrnd Diff $\left[\mathrm{m}^{2} \mathrm{~s}^{-1}\right]$ & 0.3 & 0.3 & 0.1 \\
TKE Dissipative Heating & No & No & Yes \\
\hline
\end{tabular}

be presented in a forthcoming paper; they have little effect on subtropical boundary layer clouds.

For the following discussion we focus on marine low cloud sensitivity in the southeastern Pacific for SeptemberOctober-November (SON). Even though this is only 911 months after the start of the simulations, the climatological marine low cloud bias and its sensitivity to parameter changes has already emerged, as can be seen by comparing Fig. 6a (the 1-year run) and 6d (the 50-year run). Cloudiness differences driven by synoptic timescale variability in the southeastern Pacific may affect the exact magnitudes of changes in the bias in the sensitivity experiments; by comparing the differences between the simulations in the three individual months comprising the SON period (not shown) we are confident that the signals we report are robust to synoptically driven cloudiness fluctuations.

\subsection{Results}

Figures 6 and 7 show the sensitivity of short-wave cloud radiative effect (SWCRE) and low cloud fraction over the Pacific region for SON. In these plots, panel a shows the bias of the control simulation compared to satellite-derived climatologies, and the next two panels show the difference of the control from the two sensitivity runs. The observations used in Fig. 7a are a combination of the climatological low cloud fraction from the CLOUDSAT/CALIPSO GEOPROF product (Kay and Gettelman, 2009) and the CALIPSO GOCCP product (Chepfer et al., 2010) for 2006-2010 - in each grid box the maximum low cloud fraction from the two is used. This method enhances the low cloud fraction just off the west coasts of the American and African continents because GEOPROF tends to underestimate low cloud amount because it screens out clouds with tops below $500 \mathrm{~m}$ altitude. However, GEOPROF is more accurate in general because the combination of CLOUDSAT and CALIPSO instruments can detect low clouds better when mid- and high-level clouds are present. The SWCRE observation used in Fig. 6a and d is from the Clouds and Earth's Radiant Energy System Edition 2 (CERES2, Minnis et al., 2011) for 2000-2005. In these panels, biases on the Control simulation are reduced where

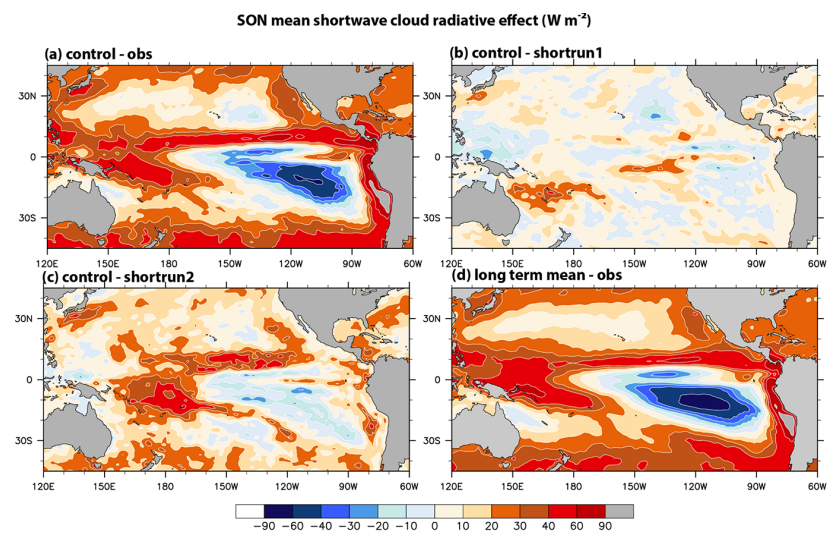

Figure 6. Short-wave cloud forcing biases and their improvements in global simulations. Panel (a) shows the bias in the control run compared to observations; panel (b) shows the difference between control and shortrun1; panel (c) shows the difference between control and shortrun2. In panels (b) and (c), the respective experiment bias has been eliminated to the extent that the pattern matches (a). See text for further explanation. Panel (d) shows the bias in the 50year control run.

the colours indicate differences of the same sign as the upper panel (e.g. blue colours where there is a blue colour in the upper panel, or vice versa).

While it would be ideal to compare model simulations to observations over the same time period, we found it technically much simpler to initialise the short GFS runs with the same initial conditions as the 50-year run rather than with initial conditions from the satellite era. Long-term trends and decadal variability in global mean downwelling surface radiation are of the order of +0.25 and $\pm 3-5 \mathrm{~W} \mathrm{~m}^{-2}$, respectively (Hinkelman et al., 2009), one to two orders of magnitude smaller than the GFS short-wave bias. Additionally, the decade 2000-2010 was one of weak El Niño-Southern Oscillation variability (http://www.esrl.noaa.gov/psd/enso/mei/). This gives us confidence that the difference in decades for which we compare means will not substantially affect our results.

In the southeastern Pacific, Control shows large positive errors of SWCRE (Fig. 6a) near the South American coast and negative errors further offshore, which corresponds clearly to the errors in marine low clouds (Fig. 7a), as discussed in Xiao et al. (2014). Shortrunl (Figs. 6b and $7 \mathrm{~b}$ ) shows small but consistent reduction of errors in low cloud fraction (less than $10 \%$ ) and SWCRE (less than $10 \mathrm{~W} \mathrm{~m}^{-2}$ ) both near the South American coast and in the open ocean, while Shortrun 2 shows similar patterns of error reduction but with much larger amplitude $-20-30 \mathrm{~W} \mathrm{~m}^{-2}$ for SWCRE. In the tropics $\left(15^{\circ} \mathrm{S}-15^{\circ} \mathrm{N}\right)$, the overextension of low clouds onto the equator from the southeastern $\mathrm{Pa}$ cific is also reduced in Shortrun2. There is also a large reduction of SWCRE errors in the Inter-Tropical Convergence Zone (ITCZ) and South Pacific Convergence Zone (SPCZ) 


\section{SON mean low cloud fraction (\%)}
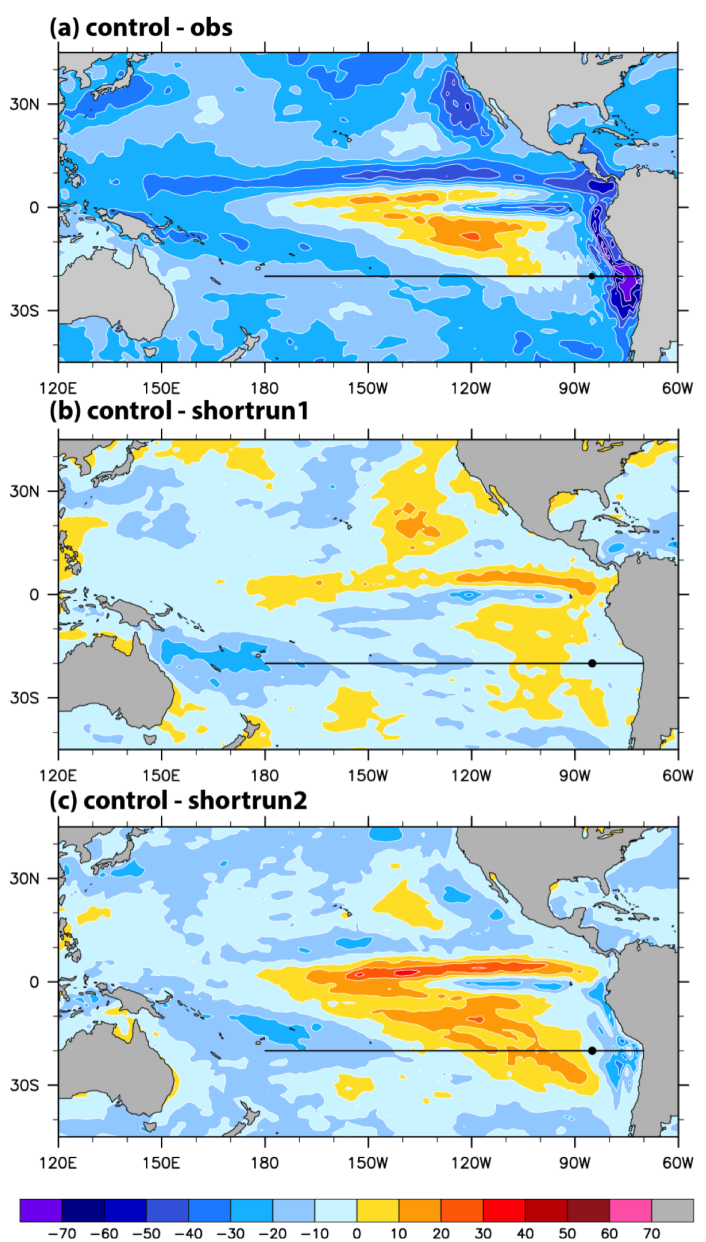

Figure 7. Cloud fraction bias and its improvement in global simulations. Panel (a) shows the bias in the control run compared to observations; panel (b) shows the difference between control and shortrun1; panel (c) shows the difference between control and shortrun2. In panels (b) and (c), the respective experiment bias has been eliminated to the extent that the pattern matches (a). See text for further explanation.

in Shortrun2, which we will discuss in more detail together with the SST response later in this section. The global mean SWCRE bias in Shortrun2, compared to that in Control, is reduced by about half, from $\sim 23$ to $\sim 11 \mathrm{~W} \mathrm{~m}^{-2}$ for the annual average of 1948 minus the CERES2 annual mean from 2000 to 2005; this bias reduction occurs persistently throughout the year.

Figure 8 shows the sensitivity of low cloud structure along $20^{\circ} \mathrm{S}$ in the East and Central Pacific for SON. In Control (Fig. 8b), the lack of clouds near the coast and the overextension offshore is clear in comparison to the CERES2-MODISCALIPSO-CLOUDSAT (CCCM) data set from the Atmospheric Science Data Center at NASA Langley Research Center, Fig. 8a.

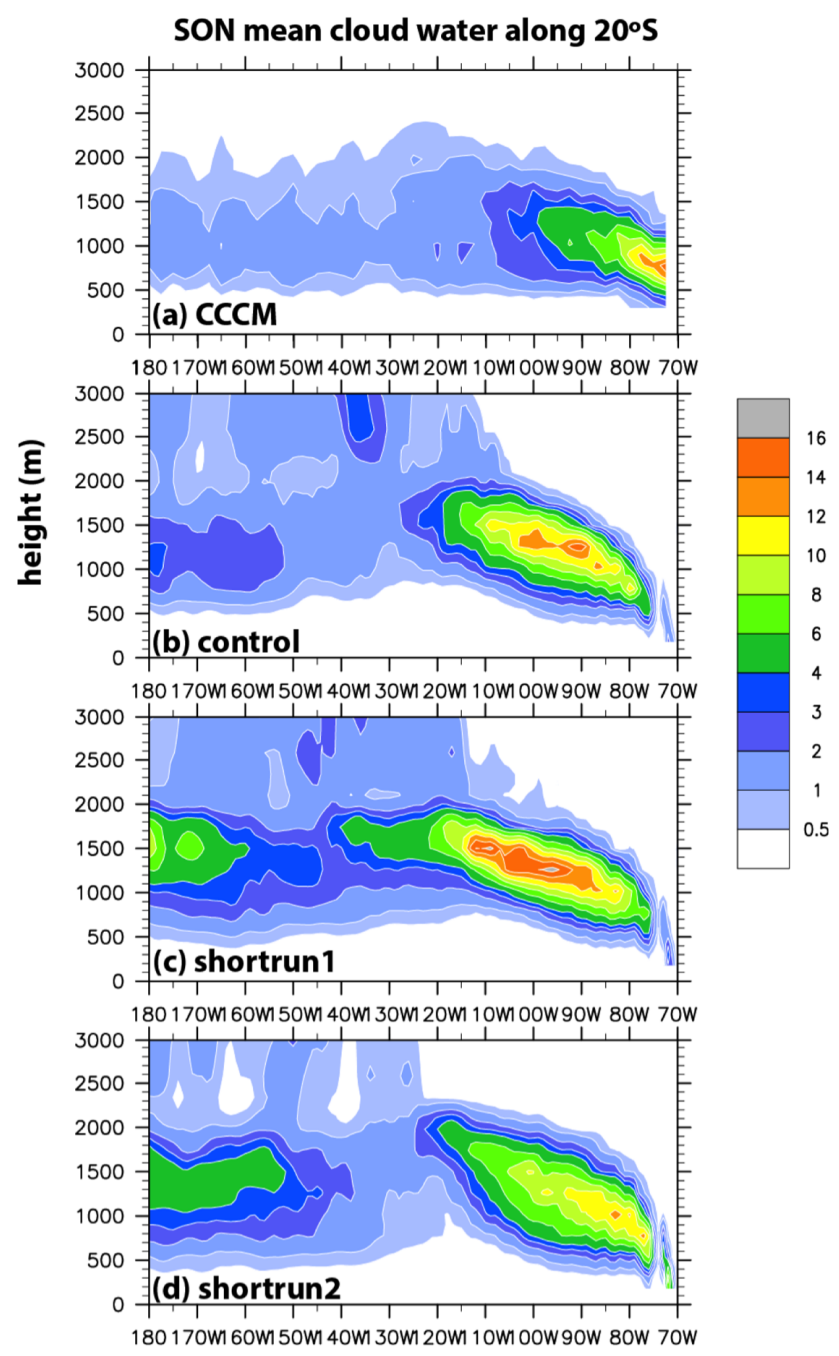

Figure 8. Cloud condensate along the $20 \mathrm{~S}$ Pacific cross section in (a) observations, (b) the control run, (c) shortrun1 and (d) shortrun2.

In Shortrun1 (Fig. 8c), the stratocumulus layer gets slightly thinner in general but the maximum in cloud water content increases and remains too far offshore, making the total error reduction small. This is likely because decreasing the shallow cumulus precipitation efficiency $c_{0}$ without changing the condensate detrainment rate $c_{1}$ simply shifts the shallow convective condensate sink from precipitation to detrainment to grid-scale cloud. Shortrun2 (Fig. 8d), on the other hand, shows reduced cloud water content offshore and increased cloud water close to the coast, more consistent with observations. However, the cloud layer in Shortrun2 extends too deep and the trade-wind inversion is weakened (not shown). Furthermore, both Shortrun1 and Shortrun2 show excessive cloud liquid water compared to CCCM in the trade cumulus regime extending across the westernmost part of the cross section, worsening a bias already present in control. 

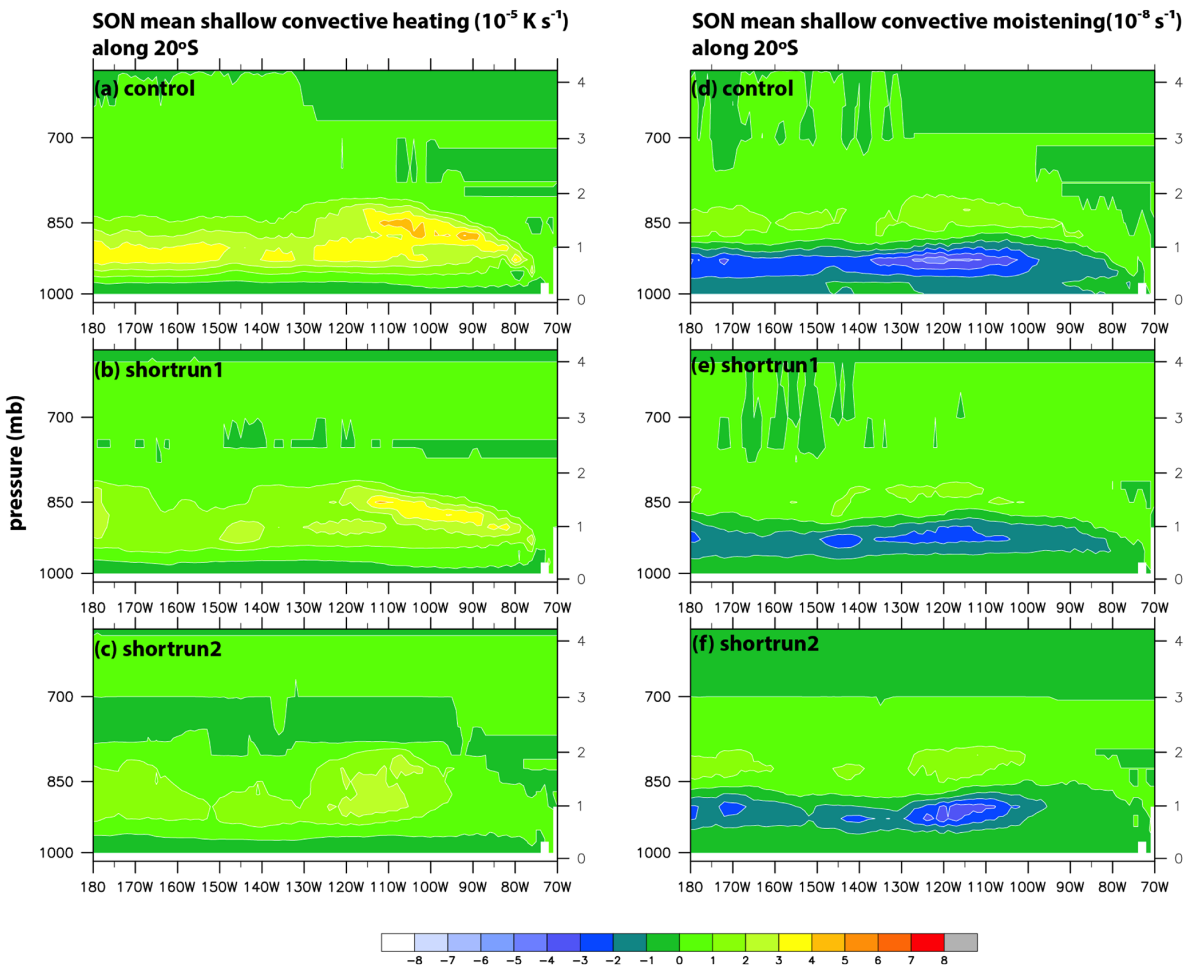

Figure 9. Shallow cumulus heating (left column) and moistening (right column) in the control run (top), shortrun1 (middle) and shortrun2 (bottom).

The cloud structure changes can be related to changes in the behaviour of the parameterised shallow convection. Figure 9 shows heating and moistening from the shallow convection scheme in each experiment along the transect. The difference between Shortrun 2 and Shortrunl east of $100^{\circ} \mathrm{W}$ shows that nearly all shallow convective activity has been eliminated in this region, which is observed to be dominated by stratocumulus clouds. Meanwhile, increasing the entrainment/detrainment parameter (one of the two differences between Shortrunl and Control) decreases mass flux in the upper cloud layers and thus reduces convective heating in the cumulus and $\mathrm{Sc}-\mathrm{Cu}$ transition regions west of $100^{\circ} \mathrm{W}$.

The SST response in SON is shown in Fig. 10 for Shortrun2. The response in Shortrun1 is small and not shown here. In Control, we see large positive SST errors near the American coasts $\left(4^{\circ} \mathrm{C}\right.$ off South American coast $)$ and negative biases to their west $\left(-2{ }^{\circ} \mathrm{C}\right.$ in the southeastern Pacific). In the tropics, there are warm SST biases of $2{ }^{\circ} \mathrm{C}$ along the ITCZ and SPCZ and near the maritime continent, and negative biases along the equator. In Shortrun2, the negative biases in the southeastern Pacific are reduced by at least half but the warm biases near the coast are worsened. In the tropics the warm biases along ITCZ and SPCZ and near the maritime continent are reduced, but the equatorial cold bias is turned into a warm bias, especially between 150 and $180^{\circ} \mathrm{W}$.

It is unlikely that changes in cloud radiative forcing directly caused the SST changes in deep convective regions, where the substantial change in short-wave cloud forcing was largely offset by a change in long-wave cloud forcing (not shown). However, reductions in excess cloud cover in the offshore southeast Pacific may contribute to the increase in SST in that region and subsequent reduction in zonal SST gradient associated with a weakening of the Walker circulation. This can also be seen in the change in SST off the Peruvian and Chilean coasts, where positive SST biases worsen despite an increase in cloud cover. This is likely due to a weakening in coastal upwelling. We found that changes in wind stress also suggest a weakening of this circulation, with a decrease in surface easterlies in the central and west Pacific and a reduction of northerlies in the southeast Pacific (not shown). Such sensitivity of the basin-wide Hadley-Walker circulation pattern to changes in marine low clouds associated with parameter changes in shallow convection and moist turbulence parameterisation is also found in other GCMs (e.g. Ma et al., 1994; Xiao et al., 2014).

\section{Future tests}

While testing parameterisation changes in climate mode for the GFS is an important aspect of our work, parameterisation development requires testing model changes effect on forecast skill as well. Typically, data assimilation tests with runs of at least 2 months are done. If forecast skill is improved, 


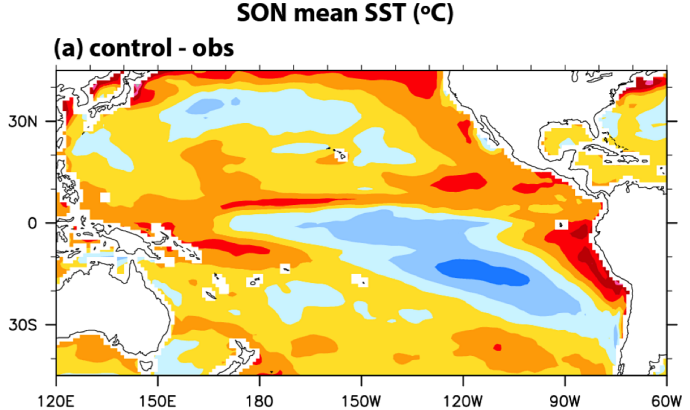

(b) control - shortrun2

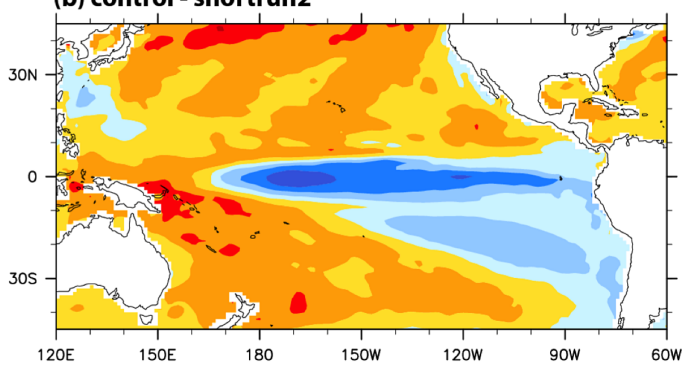

(c) long term mean - obs

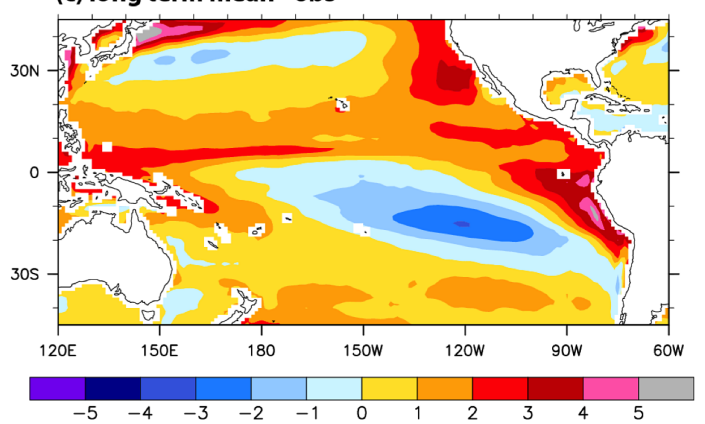

Figure 10. Pacific SST in global simulations: (a) bias in the control run; (b) the difference between control and shortrun2, and (c) bias in the 50 year control run. In panel (b), the experiment has eliminated the bias to the extent that the pattern matches that of panel (a). See text for further explanation.

especially in terms of the $500 \mathrm{hPa}$ anomaly correlation, precipitation skill over the United States, or hurricane track forecast, the change is likely to be implemented. If the skill is neutral but the climate bias is reduced, there is still a good chance of implementing the change. If the forecast skill is degraded, modifications or re-tuning of other model parameters, such as those controlling autoconversion or the critical relative humidity used for condensation, will be tried.

A short data assimilation experiment implementing the model changes included in the NewEntr and ShCuCldCover SCM results of BOMEX and DYCOMS, respectively, has been performed. Initial results suggest that, while in many respects the forecast skill is improved or neutral, the root mean square error in tropical horizontal winds is increased. As a consequence of these experiments, further work must be done before these changes can be implemented into future versions of the GFS; climate improvements must, at the very least, have a neutral impact on forecasts. Single column tests (not shown) indicate that changes in horizontal winds are not a result of cumulus momentum transport - the NewEntr change has no impact on winds in the SCM. Instead, the change is affecting horizontal pressure gradients; thus more global model tests - and possible model retuning - are needed to investigate this further. This work is underway by NCEP developers and will be reported on in a future study.

\section{Conclusions}

The NOAA stratocumulus-to-cumulus transition Climate Process Team has run sensitivity experiments to singlecolumn and global coupled versions of the NCEP-GFS model in conjunction. To improve the GFS simulation of subtropical boundary layer cloud, we used single-column simulations to identify and attribute underlying problems in the shallow convection scheme, and we then tested improvements suggested by this approach in short global coupled simulations.

In single-column mode, we found that some simple parameter changes to the shallow convection scheme improved simulated boundary layer structure and precipitation compared to LES. In particular, it is beneficial to increase cumulus lateral mixing with the environment and decrease the rate at which updraught condensate falls out as rain and is detrained to the grid scale. This shifts some of the cumulus updraught removal of water from precipitation to evaporation associated with entrainment.

However, the single-column model still over-precipitates in both shallow convective and stratiform environments. We hypothesise that this can be improved by increasing entrainment of warm, dry free-tropospheric air into the boundary layer through changes to the boundary layer scheme, by reducing autoconversion of liquid cloud water to rain in the stratiform microphysics scheme, and by reformulating shallow convective precipitation to suppress all rainfall when condensate specific humidity is small.

One-year global coupled model experiments combining these changes substantially reduce biases in subtropical low cloud fraction and short-wave cloud forcing seen in the control version of GFS. Improvements are seen in the deep convective regions as well as the subtropical boundary layer cloud regimes. Global model changes also improve SST and precipitation bias in most regions. However, underestimation of low cloud off the subtropical west coasts of the Americas remains a problem even after the changes, and increased tropical wind RMSE must be addressed before this change can be implemented in the GFS.

The CPT's focus has been on improving cloud regimes associated with the stratocumulus to trade cumulus transition. As we continue our GFS development efforts, we will take a more holistic approach, focusing on better simulation of 
global cloud cover and its radiative effects through improvements of the microphysics, cloud fraction, cumulus convection, and PBL parameterisations and their interactions.

\section{The Supplement related to this article is available online at doi:10.5194/gmd-7-2107-2014-supplement.}

Acknowledgements. This work is supported by NOAA MAPP grant GC10-670a as part of the $\mathrm{Sc}-\mathrm{Cu}$ Climate Process Team. The first author would like to thank Hua-Lu Pan at NCEP for his support and Peter Blossey at University of Washington for providing LES runs.

Edited by: J. C. Hargreaves

\section{References}

Arakawa, A. and Schubert, W. H.: Interaction of a cumulus cloud ensemble with the large-scale environment, J. Atmos. Sci., 31, 674-701, doi:10.1175/15200469(1974)031<0674:ioacce>2.0.co;2, 1974.

Bister, M. and Emanuel, K. A.: Dissipative heating and hurricane intensity, Meteorol. Atmos. Phys., 65, 233-240, 1998.

Bretherton, C. S., McCaa, J. R., and Grenier, H.: A new parameterization for shallow cumulus convection and its application to marine subtropical cloud-topped boundary layers. Part I: Description and 1D results, Mon. Weather Rev., 132, 864-882, doi:10.1175/1520-0493(2004)132<0864:anpfsc>2.0.co;2, 2004.

Chepfer, H., Bony, S., Winker, D., Cesana, G., Dufresne, J. L., Minnis, P., Stubenrauch, C. J., and Zeng, S.: The GCM-Oriented CALIPSO Cloud Product (CALIPSO-GOCCP), J. Geophys. Res.-Atmos., 115, D00H16, doi:10.1029/2009jd012251, 2010.

Chou, M. D., Suarez, M. J., Ho, C. H., Yan, M. M. H., and Lee, K. T.: Parameterizations for cloud overlapping and shortwave single-scattering properties for use in general circulation and cloud ensemble models, J. Climate, 11, 202-214, doi:10.1175/1520-0442(1998)011<0202:pfcoas>2.0.co;2, 1998.

Grabowski, W. W., Bechtold, P., Cheng, A., Forbes, R., Halliwell, C., Khairoutdinov, M., Lang, S., Nasuno, T., Petch, J., Tao, W. K., Wong, R., Wu, X., and Xu, K. M.: Daytime convective development over land: A model intercomparison based on LBA observations, Q. J. Roy. Meteorol. Soc., 132, 317-344, doi:10.1256/qj.04.147, 2006.

Grant, A. L. M. and Brown, A. R.: A similarity hypothesis for shallow-cumulus transports, Q. J. Roy. Meteorol. Soc., 125, 1913-1936, doi:10.1256/smsqj.55801, 1999.

Griffies, S. M., Gnanadesikan, A., Dixon, K. W., Dunne, J. P., Gerdes, R., Harrison, M. J., Rosati, A., Russell, J. L., Samuels, B. L., Spelman, M. J., Winton, M., and Zhang, R.: Formulation of an ocean model for global climate simulations, Ocean Sci., 1, 45-79, doi:10.5194/os-1-45-2005, 2005.

Han, J. and Pan, H.-L.: Revision of Convection and Vertical Diffusion Schemes in the NCEP Global Forecast System, Weather Forecast., 26, 520-533, doi:10.1175/waf-d-10-05038.1, 2011.
Hinkelman, L. M., Stackhouse Jr., P. W., Wielicki, B. A., Zhang, T., and Wilson, S. R.: Surface insolation trends from satellite and ground measurements: Comparisons and challenges, J. Geophys. Res., 114, 1-18, doi:10.1029/2008JD011004, 2009.

Holland, J. Z. and Rasmusson, E. M.: Measurements of atmospheric mass, energy, and momentum budgets over a 500kilometer square of tropical ocean, Mon. Weather Rev., 101, 4455, doi:10.1175/1520-0493(1973)101<0044:motame>2.3.co;2, 1973.

Hong, S. Y. and Pan, H. L.: Nonlocal boundary layer vertical diffusion in a Medium-Range Forecast Model, Mon. Weather Rev., 124, 2322-2339, doi:10.1175/15200493(1996)124<2322:nblvdi>2.0.co;2, 1996.

Hou, Y., Moorthi, S., and Compana, K.: Parameterization of solar radiation transfer in NCEP models, NCEP Office Note, \#441, available at: http://www.emc.ncep.noaa.gov/officenotes/ FullTOC.html\#2000, 2002.

Kalnay, E., Kanamitsu, M., Kistler, R., Collins, W., Deaven, D., Gandin, L., Iredell, M., Saha, S., White, G., Woollen, J., Zhu, Y., Chelliah, M., Ebisuzaki, W., Higgins, W., Janowiak, J., Mo, K. C., Ropelewski, C., Wang, J., Leetmaa, A., Reynolds, R., Jenne, R., and Joseph, D.: The NCEP/NCAR 40-year reanalysis project, B. Am. Meteorol. Soc., 77, 437-471, doi:10.1175/15200477(1996)077<0437:tnyrp>2.0.co;2, 1996.

Kay, J. E. and Gettelman, A.: Cloud influence on and response to seasonal Arctic sea ice loss, J. Geophys. Res.-Atmos., 114, D18204, doi:10.1029/2009JD011773, 2009.

Khairoutdinov, M. F. and Randall, D. A.: Cloud resolving modeling of the ARM summer 1997 IOP: Model formulation, results, uncertainties, and sensitivities, J. Atmos. Sci., 60, 607-625, doi:10.1175/1520-0469(2003)060<0607:crmota>2.0.co;2, 2003.

Lock, A. P., Brown, A. R., Bush, M. R., Martin, G. M., and Smith, R. N. B.: A new boundary layer mixing scheme. Part I: Scheme description and single-column model tests, Mon. Weather Rev., 128, 3187-3199, doi:10.1175/15200493(2000)128<3187:anblms>2.0.co;2, 2000.

Lord, S.: Development and observational verification of cumulus cloud parameterization, $\mathrm{Ph}$. D. Thesis, University of California, Los Angeles, 1978.

Luo, Y. L., Krueger, S. K., and Moorthi, S.: Cloud properties simulated by a single-column model. Part I: Comparison to cloud radar observations of cirrus clouds, J. Atmos. Sci., 62, 14281445, doi:10.1175/jas3425.1, 2005

Ma, C. C., Mechoso, C. R., Arakawa, A., and Farrara, J. D.: Sensitivity of a coupled ocean-atmosphere model to physical parameterizations, J. Climate, 7, 1883-1896, doi:10.1175/15200442(1994)007<1883:soacom>2.0.co;2, 1994.

Mlawer, E. J., Taubman, S. J., Brown, P. D., Iacono, M. J., and Clough, S. A.: Radiative transfer for inhomogeneous atmospheres: RRTM, a validated correlated-k model for the longwave, J. Geophys. Res.-Atmos., 102, 16663-16682, doi:10.1029/97jd00237, 1997.

Moorthi, S., Pan, H.-L., and Caplan, P.: Changes to the 2001 NCEP operational MRF/AVN global analysis/forecast system, NWS Tech. Procedures Bulletin, 484, available at: http://www.nws. noaa.gov/om/tpb/484.htm (last access: 9 September 2014), 2001

Neggers, R. A. J., Koehler, M., and Beljaars, A. C. M.: A Dual Mass Flux Framework for Boundary Layer Convection. Part I: Trans- 
port, J. Atmos. Sci., 66, 1465-1487, doi:10.1175/2008jas2635.1, 2009.

Pan, H. and $\mathrm{Wu}, \mathrm{W}$. : Implementing a mass flux convective parameterization package for the NMC Medium- Range Forecast model, NMC Office Note, 409, available at: http://www. emc.ncep.noaa.gov/officenotes/FullTOC.html\#1990 (last access: 9 September 2014), 1995.

Randall, D., Krueger, S., Bretherton, C., Curry, J., Duynkerke, P., Moncrieff, M., Ryan, B., Starr, D., Miller, M., Rossow, W., Tselioudis, G., and Wielicki, B.: Confronting models with data The GEWEX cloud systems study, B. Am. Meteorol. Soc., 84, 455-469, doi:10.1175/bams-84-4-455, 2003.

Saha, S., Nadiga, S., Thiaw, C., Wang, J., Wang, W., Zhang, Q., Van den Dool, H. M., Pan, H. L., Moorthi, S., Behringer, D., Stokes, D., Pena, M., Lord, S., White, G., Ebisuzaki, W., Peng, P., and Xie, P.: The NCEP Climate Forecast System, J. Climate, 19, 3483-3517, doi:10.1175/jcli3812.1, 2006.

Saha, S., Moorthi, S., Pan, H.-L., Wu, X., Wang, J., Nadiga, S., Tripp, P., Kistler, R., Woollen, J., Behringer, D., Liu, H., Stokes, D., Grumbine, R., Gayno, G., Wang, J., Hou, Y.-T., Chuang, H.Y., Juang, H.-M. H., Sela, J., Iredell, M., Treadon, R., Kleist, D., Van Delst, P., Keyser, D., Derber, J., Ek, M., Meng, J., Wei, H., Yang, R., Lord, S., Van den Dool, H., Kumar, A., Wang, W., Long, C., Chelliah, M., Xue, Y., Huang, B., Schemm, J.-K., Ebisuzaki, W., Lin, R., Xie, P., Chen, M., Zhou, S., Higgins, W., Zou, C.-Z., Liu, Q., Chen, Y., Han, Y., Cucurull, L., Reynolds, R. W., Rutledge, G., and Goldberg, M.: The NCEP climate forecast system reanalysis, B. Am. Meteorol. Soc., 91, 1015-1057, doi:10.1175/2010bams3001.1, 2010.

Sela, J.: Implementation of the sigma pressure hybrid coordinate into GFS, Tech. rep., NCEP office Note, 2009.

Siebesma, A. P. and Cuijpers, J. W. M.: Evaluation of parametric assumptions for shallow cumulus convection, J. Atmos. Sci., 52, 650-666, doi:10.1175/15200469(1995)052<0650:eopafs>2.0.co;2, 1995.

Siebesma, A. P., Bretherton, C. S., Brown, A., Chlond, A., Cuxart, J., Duynkerke, P. G., Jiang, H. L., Khairoutdinov, M., Lewellen, D., Moeng, C. H., Sanchez, E., Stevens, B., and Stevens, D. E.: A large eddy simulation intercomparison study of shallow cumulus convection, J. Atmos. Sci., 60, 1201-1219, doi:10.1175/15200469(2003)60<1201:alesis>2.0.co;2, 2003.
Stevens, B., Lenschow, D. H., Vali, G., Gerber, H., Bandy, A., Blomquist, B., Brenguier, J. L., Bretherton, C. S., Burnet, F., Campos, T., Chai, S., Faloona, I., Friesen, D., Haimov, S., Laursen, K., Lilly, D. K., Loehrer, S. M., Malinowski, S. P., Morley, B., Petters, M. D., Rogers, D. C., Russell, L., SavicJovac, V., Snider, J. R., Straub, D., Szumowski, M. J., Takagi, H., Thornton, D. C., Tschudi, M., Twohy, C., Wetzel, M., and van Zanten, M. C.: Dynamics and chemistry of marine stratocumulus - DYCOMS-II, B. Am. Meteorol. Soc., 84, 579-593, doi:10.1175/BAMS-84-5-579, 2003.

Stevens, B., Moeng, C. H., Ackerman, A. S., Bretherton, C. S., Chlond, A., De Roode, S., Edwards, J., Golaz, J. C., Jiang, H. L., Khairoutdinov, M., Kirkpatrick, M. P., Lewellen, D. C., Lock, A., Muller, F., Stevens, D. E., Whelan, E., and Zhu, P.: Evaluation of large-Eddy simulations via observations of nocturnal marine stratocumulus, Mon. Weather Rev., 133, 1443-1462, doi:10.1175/mwr2930.1, 2005.

Sundqvist, H.: Parameterization scheme for non-convective condensation including prediction of cloud water content, Q. J. Roy. Meteorol. Soc., 104, 677-690, doi:10.1002/qj.49710444110, 1978.

Troen, I. and L.: A simple model of the atmospheric boundary layer - sensitivity to surface evaporation, Bound.-Lay. Meteorol., 37, 129-148, doi:10.1007/bf00122760, 1986.

Xiao, H., Mechoso, C. R., Sun, R., Han, J., Park, S., Hannay, S., Teixeira, J., and Bretherton, C.: Diagnosis of Marine Low Clouds Simulation in the NCAR Community Earth System Model (CESM) and the NCEP Global Forecast System (GFS)Modular Ocean Model v4 (MOM4) coupled model, Clim. Dynam., 43, 737-752, 2014.

Xu, K. M. and Randall, D. A.: A semiempirical cloudiness parameterization for use in climate models, J. Atmos. Sci., 53, 3084 3102, doi:10.1175/1520-0469(1996)053<3084:ascpfu>2.0.co;2, 1996.

Zhao, Q. Y. and Carr, F. H.: A prognostic cloud scheme for operational NWP models, Mon. Weather Rev., 125, 1931-1953, doi:10.1175/1520-0493(1997)125<1931:apcsfo>2.0.co;2, 1997.

Zhu, P., Bretherton, C. S., Kohler, M., Cheng, A. N., Chlond, A., Geng, Q. Z., Austin, P., Golaz, J. C., Lenderink, G., Lock, A., and Stevens, B.: Intercomparison and interpretation of singlecolumn model simulations of a nocturnal stratocumulus-topped marine boundary layer, Mon. Weather Rev., 133, 2741-2758, doi:10.1175/mwr2997.1, 2005. 